\title{
FEW LARGE AND MANY SMALL: HIERARCHY IN MOVEMENT ON EARTH
}

\author{
S. LORENTE ${ }^{1} \&$ A. BEJAN ${ }^{2}$ \\ ${ }^{1}$ University of Toulouse, INSA, Civil Engineering Department, France. \\ ${ }^{2}$ Duke University, Department of Mechanical Engineering and Materials Science, USA.
}

\begin{abstract}
Movement on earth is effected by bodies (e.g. river channels, animals, vehicles) of seemingly random scales, large and small. Here we use the constructal law and the design of 'distributed energy systems' to show that the large must be few and the small many, in particular proportions that are required for greater access for movement on areas. First, we demonstrate that mass movement per kilogram moved and kilometer traveled requires less fuel on larger vehicles. The thermodynamics basis of this is the same as for the effect of size on the efficiency of motors, vascular flow architectures and river basins. The same principle dictates that on every vehicle the motor mass must scale with the structural mass, and with the total mass. In addition, larger masses must move on areas to greater distances, and a characteristic number of smaller masses must be allocated to a larger mass to travel, on the same area element.
\end{abstract}

Keywords: constructal law, distributed energy systems, multiscale flow, river basins, scaling up, size effect, vascular design.

\section{DISTRIBUTED ENERGY SYSTEMS}

The designs of animals show that the generation and use of motive power is distributed throughout the body. It is not centered in a single spot, nodule or organ. The animal muscle is like a quilt of patches served by two kinds of flow systems: (a) tissues that generate movement (contraction), and (b) vascularization that feeds, cleanses, and endows the tissue with the ability to sense and act. So perfect is the allocation of power generation to the networks for supply and distribution that the untrained eye sees the tissue as one or, at the most, as a complicated (multiscale) porous flow structure. The allocating of one flow system to the other flow system in the same confined space is the secret of the design. How are such designs made? How do they function?

Like the animal muscle, the patchwork of power generation, distribution, and use happens naturally. Unlike the animal muscle, which has spent millions of years in the factory of evolution, our energy systems evolve in front of our eyes. They morph while they grow. They produce more power, and they produce the power more efficiently. Why?

These features are fundamental in the context of a sustainable energy future for our planet [1]. The inhabited surface of the earth is covered flow designs with the same two main features:

1. Nodes, large channels of power generation, embedded in

2. Networks of supply and distribution.

Features (1) and (2) are allocated to elemental areas, forming a patchwork that covers countries and continents. One example is the evolution of air mass transit: its map has history and memory. In time, new channels appear and old ones become thicker.

Why this evolutionary phenomenon of 'allocation' phenomenon occurs is the key question. The flows of nature evolve in time to flow more and more easily, in accord with the constructal law: 'For a finite-size flow system to persist in time (to live), its configuration must change such that it provides greater and greater access to its currents' [2]. They attain this ever improving quality through

(C) 2010 WIT Press, www.witpress.com

ISSN: 1755-7437 (paper format), ISSN: 1755-7445 (online), http://journals.witpress.com

DOI: 10.2495/DNE-V5-N3-254-267 
the generation of configuration. Existing designs (literally, drawings) are replaced by new designs that flow more easily. Every flow system has its movie, be it in nature or on our drawing boards. In this mental viewing fit all the evolutionary scenarios of biology, the emergence of river basins and climate, and the evolution of technologies toward greater efficiency [1-11].

Age matters in the evolution phenomena, and it is good for flow performance. The river basin digs its channels better and better, and the channels stay in place. The channels have hierarchy: a few large channels flow in harmony with the many small channels. A sudden downpour is served well by the 'memory' built into the old design.

Recent theoretical work on the constructal-law basis of animal locomotion [12] has shown that for all types of locomotion (running, flying, swimming), the animal force is roughly equal to the body weight, and the minimum work that the body performs is proportional to the body weight times the distance traveled. The consumed food or fuel is 'converted' into mass moved over a distance. Our cars, construction sites, and everything else that we do are the result of this conversion. All the animals and all of us consume food and fuel, and the result is the shaping, reshaping and mixing of the earth's surface.

The question of how mass moves on earth traces the fundamental direction of this paper. In addition to the importance of these fundamentals to the human design of a sustainable and safe future, we see three more reasons for considering this direction of inquiry:

First, the need to consider the whole is universal. Yet, most of the research on energy science and engineering is devoted to the 'energy' side, that is, to more efficient and cleaner production (features of type 1 at the start of this section). The remainder of the effort is devoted to the 'environment', that is, to the human flow networks that interact with the environment (features of type 2). In constructal theory, energy (1) and the environment (2) are contemplated together from the beginning, because their configurations morph together, hand in glove. From the smallest elemental areas, features (1) and (2) come together and form a self-sustaining and long lasting flow tissue, and the tissue is the design, the black on white.

Second, the widespread occurrence of distributed energy systems in nature is a very loud hint that the future of global energy design belongs to distributed, vascularized systems [1]. In nature, distributed energy systems occur not only in animal design but also throughout the inanimate flow realm. Every channel in a river basin is a combination of (1) motive power (the slope, i.e. the driving gravitational potential energy); (2) distribution, use, dissipation (friction along the channel); and the allocation of (1) and (2) to the elemental area bathed by the channel. The time arrow of evolution in natural flow systems points toward distributed energy systems.

Third, natural flow architectures rule the day because they have evolved into flow configurations that flow easier and easier, for example, tree-shaped flows oriented point-to-area or area-to-point. They survived because they are free to adapt; that is, their configurations are malleable in spite of the constraints. Freedom is good for design [1].

Technology, like the river basin, evolves by morphing, improving and spreading. Technology enables our movement. There is no difference between natural flow architectures and the transportation architectures for humans and goods, which are powered by sources designed and positioned by humans on the landscape.

\section{FEW LARGE AND MANY SMALL, TOGETHER}

With the constructal law, we have begun to predict the emergence of multi-scale designs on the landscape in three highly dissimilar domains. First was the distribution of city sizes and numbers on a continent, where we predicted the observed Zipf-type distribution of city sizes vs. city ranks [13]. The prediction followed from the argument that on every area element of the territory the number of those working on the area (e.g. agriculturers) must be proportional to the number of the city dwellers, 
and both numbers must be proportional to the area allocated to them. This construction rule generates the multi-scale distribution of demography and is represented theoretically as a straight line on a $\log -\log$ field. The line moves upward, parallel to itself, because the evolution of technology: each area element sustains more people in time, on the land and in its allocated human settlement.

The second example was the distribution of fuel use for heating [1]. Humanity needs heating all over the globe, and for this reason the burning of fuel occurs all over the globe. Key is the observation that all the generated heat (the used and the unused) is eventually discharged as heat into the environment (Fig. 1). The challenge is to channel most of this heat through our homes, power plants and enterprises before discharging it into the environment. The challenge is to place humans and enterprises in the right places on the landscape, as optimally positioned interceptors. When this tapestry of interceptors of heat is designed from principle, three major features emerge:

- The heating needs of humanity are met by burning minimum fuel.

- The total heating dumped into the environment is the smallest that it can be.

- The movement of humanity on the landscape is maximized per unit of fuel consumed.

Heat is being lost for two reasons: heat leaks from the furnaces, and heat leaks from the pipes that distribute the hot water. We found that when the individual need for hot water is small enough, the global design with least heat loss per user is the design in which each user relies on one heater, without pipes for hot water distribution. As the amount of hot water used by each individual increases, the more economical way is to use a central heater with radial lines of distribution to an optimal-size cluster of users. As the individual hot-water need increases with the evolution of the standard of living, even more economical are the dendritic clusters, which are larger and more complex. The landscape is covered by design, but the design changes abruptly from one configuration to the next, as time passes. This is the essential aspect of technology evolution, and how it is anticipated based on principle.

The third domain in which we predicted the same emergence of multi-scale configuration on the landscape is the distribution of tree sizes and numbers on the forest floor [1, 14]. With the constructal law we deduced the configuration of each tree (root, trunk, canopy) as a flow system morphing to facilitate two flows: water and stresses. This led to several predictions of vegetation design

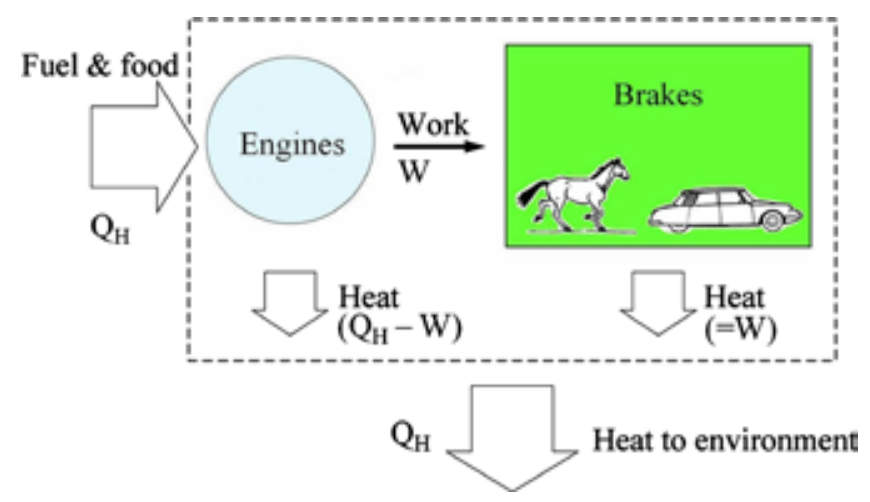

Figure 1: The 'engine + brake' systems of civilization dissipate the work produced with food and fuel, and reject it as heat to the ambient. The lasting result of power generation and consumption is the moving of mass on earth, i.e. the mixing of the earth's crust. 
(e.g. Leonardo's rule, Fibonacci sequence, Huber's rule), including the proportionality between the mass flow rate (from ground to air) through one tree and the diameter of the canopy. Next, from the tendency of the entire forest floor to transfer water to the atmosphere came the multi-patch design of the forest floor. The predicted distribution of tree sizes vs. rank is again of the Zipf type - a descending line of $\log$ (size) vs. $\log$ (rank) - and is the second instance in which we discovered the Zipf distribution as a consequence of the constructal law.

\section{MOTOR MASS VERSUS STRUCTURAL MASS}

An important consequence of the animal locomotion scaling relations [12] is that every animal spends its work of locomotion (W) on moving its weight to a distance. For all the animals (swimmers, runners, flyers) in the enormous body mass range $10^{-6}-10^{3} \mathrm{~kg}$, the mechanical work (W) performed by the animal per distance traveled $(\mathrm{L})$ is proportional to the body weight $(\mathrm{Mg})$,

$$
\mathrm{W} \sim \mu \mathrm{MgL}
$$

Here $\mathrm{g}$ is the gravitational acceleration, and $\mu$ is a dimensionless factor of order 1 . For flyers, the $\mu$ factor is of order $1 / 10$, while for swimmers it is of order 1 . For runners, the $\mu$ factor is between $1 / 10$ and 1 , and depends on the condition of the running surface and the importance of air drag relative to friction on the ground. For example, running through snow, mud and sand is represented by a $\mu$ value close to 1 , i.e. close to swimming. Large animals running at high speeds on flat and dry surfaces have $\mu$ values closer to $1 / 10$, i.e. closer to flyers.

Note that the animal effort formula, eqn (1), is the same as the formula for the work performed and dissipated by any of our vehicles, seaborne, terrestrial or airborne. The engine work scales as the weight of the vehicle $(\mathrm{Mg})$ times the distance $(\mathrm{L})$ to which the weight is moved. Note the similarity between eqn (1) and the formula for the work done during sliding with friction on a solid surface, where $\mu$ is the Coulomb coefficient of friction.

This brings us to the unifying image presented in Fig. 1. Every mass that is driven to move on earth functions as a converter of fuel (or food) into mass moved to a distance. The 'engines' represent the muscles of animals and the engines of vehicles. Every engine converts heat derived from fuel $\left(\mathrm{Q}_{\mathrm{H}}\right)$ into work for locomotion $(\mathrm{W})$ and heat rejected to the environment $\left(\mathrm{Q}_{\mathrm{H}}-\mathrm{W}\right)$. Every moving body dissipates its locomotion work $(\mathrm{W})$ by friction against the environment that it penetrates. The dissipated work is rejected entirely as heat to the environment.

In sum, every animal and vehicle is an 'engine + brake' system. The original heat input $\left(\mathrm{Q}_{\mathrm{H}}\right)$ is dissipated entirely to the environment. The animals and vehicles are just intermediaries through which $\mathrm{Q}_{\mathrm{H}}$ flows. The net effect of the consumption of fuel and food (i.e. the effect of the flow of heat, from fuel to ambient) is the movement of the mass (M) of the engine + brake system to a distance $\mathrm{L}$ in proportion to the work $\mathrm{W}$, in accordance with eqn (1).

Figure 2 is a brief thermodynamics review of how every engine (animal or man made) converts fuel or food $\left(\dot{\mathrm{m}}_{\mathrm{f}}[\mathrm{kg} / \mathrm{s}]\right)$ into power $(\dot{\mathrm{W}}[\mathrm{W}])$ in steady state. The engine is the aggregate system defined with dotted line. In the upper part, the fuel stream is mixed with air and burned to produce heat of combustion at the rate $\dot{\mathrm{Q}}_{\mathrm{H}}=\dot{\mathrm{m}}_{\mathrm{f}} \mathrm{HV}$, where the factor $\mathrm{HV}[\mathrm{J} / \mathrm{kg}]$ is the heating value of the fuel. In the lower part of Fig. 2, the heating rate $\dot{Q}_{H}$ is converted into power $\dot{W}$ (work per unit time). The energy conversion efficiency of the aggregate system is $\eta=\dot{W} / \dot{Q}_{H}$, which means that $\dot{\mathrm{W}}=\eta \dot{\mathrm{m}}_{\mathrm{f}} \mathrm{HV}$. If the movement of the engine + brake system requires the time $t$, then the work of locomotion is $\mathrm{W}=\dot{\mathrm{W}} \mathrm{t}$, the amount of fuel spent is $\mathrm{m}_{\mathrm{f}}=\dot{\mathrm{m}}_{\mathrm{f}} \mathrm{t}$, and

$$
\mathrm{W}=\eta \mathrm{m}_{\mathrm{f}} \mathrm{HV}
$$




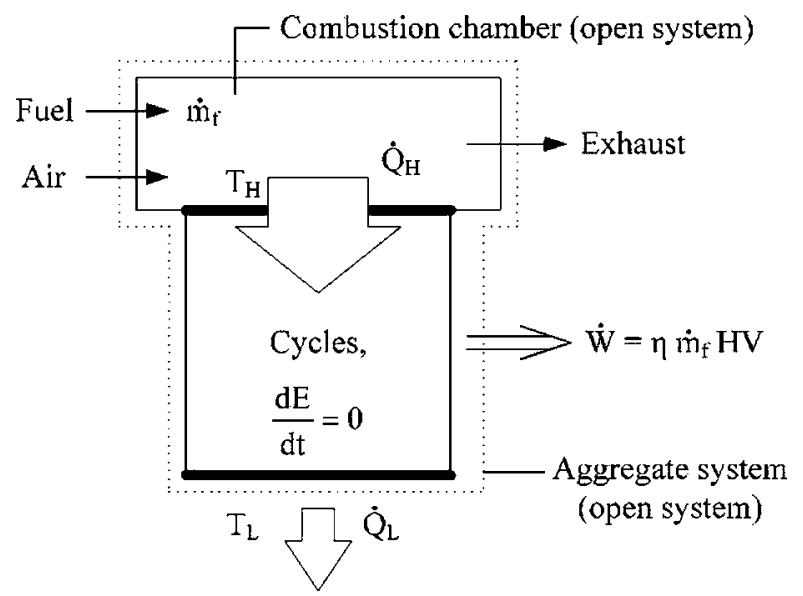

Figure 2: A heat engine executing cycles, or operating in steady state receives its heat input from a steady-combustion chamber that burns fuel at the rate $\dot{\mathrm{m}}_{\mathrm{f}}[\mathrm{kg} / \mathrm{s}]$. The heating produced by the combustion chamber $\dot{\mathrm{Q}}_{\mathrm{H}}$ is proportional to the fuel flow rate $\dot{\mathrm{m}}_{\mathrm{f}}$. The power output is $\dot{W}=\eta \dot{Q}_{H}$, where $\eta$ is the 'first law' efficiency of the engine. The power $\dot{W}$ is proportional to the product $\eta \dot{\mathrm{m}}_{\mathrm{f}}$. For more power, we need two design changes: more fuel consumption and higher efficiencies.

For more movement (W, or $\eta \mathrm{MgL}$ ), the system must use more fuel $\left(\mathrm{m}_{\mathrm{f}}\right)$, and must use it more efficiently $(\eta)$. Conversely, if the movement (W) is specified, then it can be accomplished with less fuel when the efficiency $\eta$ is greater,

$$
\mathrm{m}_{\mathrm{f}}=\frac{\mu \mathrm{MgL}}{\eta \mathrm{HV}}
$$

The efficiencies of man made power plants (moving or stationary) have been increasing in time (Fig. 3, top). Less known is the size effect documented in the lower part of Fig. 3: the more efficient engines are larger [2,15]. Both evolutionary phenomena, the top and the bottom of Fig. 3, are linked to design changes that make it easier for all the currents (fluid, heat) to flow through the flow system. This is the time direction of design generation and evolution recognized as the constructal law.

In the lower part of Fig. 3, the size of the power plant is represented by its net power output. A larger size also means larger duct cross-sections for fluid flow, larger surfaces for heat transfer, larger turbines (larger flow passages), etc. A larger size means more mass installed in the motor, $\mathrm{M}_{\mathrm{m}}$.

The monotonic relation between efficiency $(\eta)$ and motor mass $\left(M_{m}\right)$ can be anticipated theoretically by taking into account the resistances encountered by the flow of fluid and heat inside the motor. The key feature of the increase of $\eta$ with $\mathrm{M}_{\mathrm{m}}$ is the diminishing returns. The efficiency cannot be greater than the Carnot efficiency, and this means that the rate at which $\eta$ increases with size must decrease as the size increases,

$$
\frac{\mathrm{d}^{2} \eta}{\mathrm{dM}_{\mathrm{m}}^{2}}<0
$$



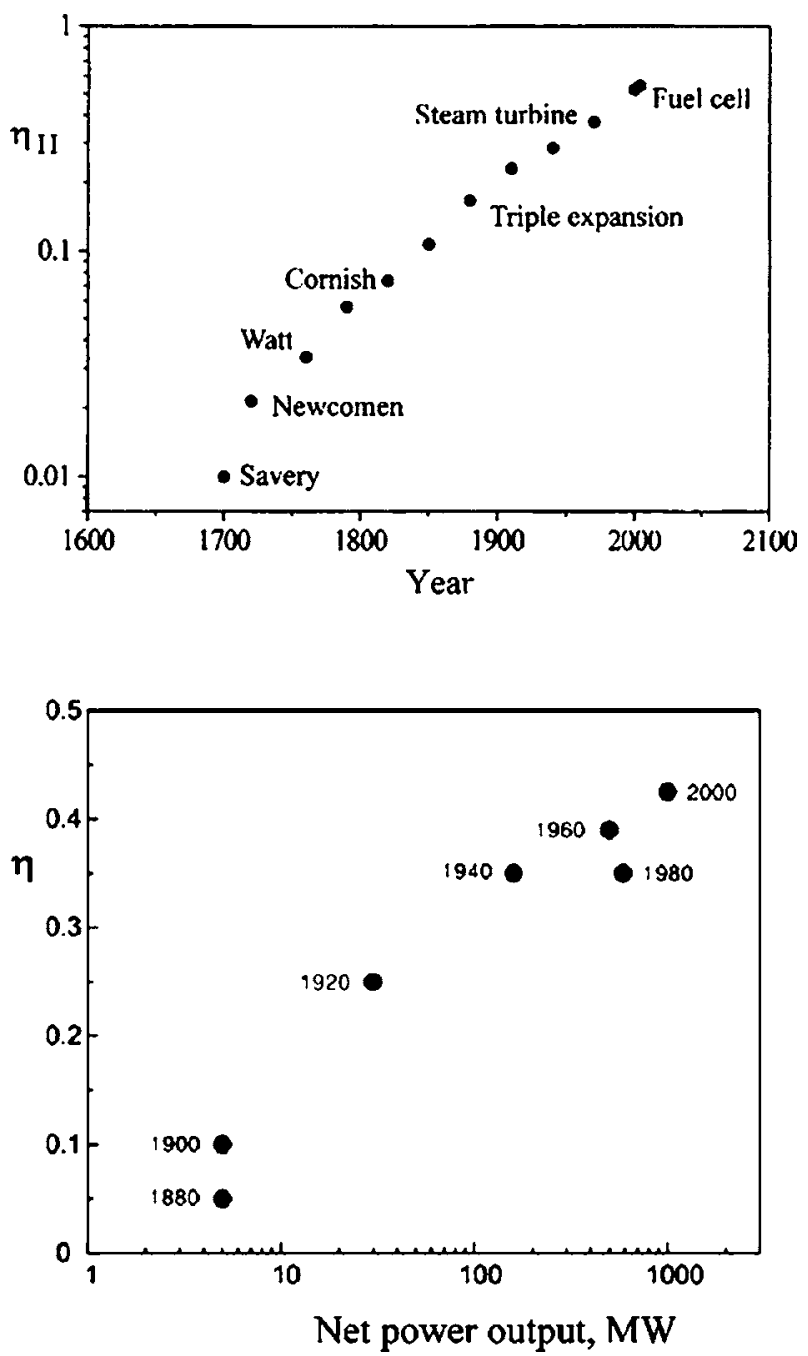

Figure 3: The efficiencies of heat engines have been increasing in time, and the more efficient are larger [15]. The efficiency $\eta$ is $\dot{\mathrm{W}} / \dot{\mathrm{Q}}_{\mathrm{H}}$, cf. Fig. 2 (top). The second law efficiency $\eta_{\mathrm{II}}$ is the ratio $\dot{\mathrm{W}} / \dot{\mathrm{W}}_{\text {rev }}$, where $\dot{\mathrm{W}}_{\text {rev }}$ is the power generated with the same heat input $\dot{\mathrm{Q}}_{\mathrm{H}}$ in the theoretical limit of reversible operation.

The relation $\eta\left(\mathrm{M}_{\mathrm{m}}\right)$ is monotonic and concave. An adequate approximation of such a relation in the vicinity of the present-time values for $\eta$ and $\mathrm{M}_{\mathrm{m}}$ is

$$
\eta=\mathrm{C}_{1} \mathrm{M}_{\mathrm{m}}^{\mathrm{a}}
$$

where $\alpha$ is less than 1 , and $\mathrm{C}_{1}$ is a constant.

The concavity of $\eta$ vs. $M_{m}$ derives from the fact that $\alpha$ is less than 1 . As we will show, this feature is key. In the fuel requirement, eqn (3), the moving mass $\mathrm{M}$ has two main parts, the solid structure (the stress-loaded structure of the vehicle, or the skeletal mass of the animal, $\mathbf{M}_{\mathrm{s}}$ ) and the structure 
permeated by flows of fluid, heat and other currents (the 'motor' structure of the vehicle, or the 'muscle' mass, $\mathrm{M}_{\mathrm{m}}$ ):

$$
\mathrm{M}=\mathrm{M}_{\mathrm{s}}+\mathrm{M}_{\mathrm{m}}
$$

Combining eqns (5) and (6) with eqn (3) we find that the amount of consumed fuel depends on how the vehicle mass $M$ is allocated to $M_{s}$ and $M_{m}$,

$$
\mathrm{m}_{\mathrm{f}}=\frac{\mu \mathrm{gL}}{\mathrm{C}_{1} \mathrm{HV}} \cdot \frac{\mathrm{M}_{\mathrm{s}}+\mathrm{M}_{\mathrm{m}}}{\mathrm{M}_{\mathrm{m}}^{\mathrm{a}}}
$$

In the limit of small motor masses, $\mathrm{M}_{\mathrm{m}}<\mathrm{M}_{\mathrm{s}}$, the fuel requirement increases as $\mathrm{M}_{\mathrm{s}} / \mathrm{M}_{\mathrm{m}}^{\mathrm{a}}$. In the limit of large motor masses, $M_{m}>M$, the fuel increases as $M_{m}^{1-a}$, because $1-a>0$. The fuel used is minimal in between, at the intersection of the two asymptotes, $\mathrm{M}_{\mathrm{s}} / \mathrm{M}_{\mathrm{m}}^{\mathrm{a}} \sim \mathrm{M}_{\mathrm{m}}^{1-\mathrm{a}}$, which is the design where the motor mass scales with the structural mass,

$$
\mathrm{M}_{\mathrm{m}} \sim \mathrm{M}_{\mathrm{s}}
$$

This conclusion is robust because it is independent of the value of $\alpha$, as long as $\alpha<1$.

\section{LARGER MOTORS ARE MORE EFFICIENT}

Here we predict how 'size' should influence the efficiency of any engine. The finiteness of sizes is why currents must overcome flow resistances, degrading in this way the global efficiency of the engine. Consider the model of Fig. 4, where the engine is a closed thermodynamic system in steady

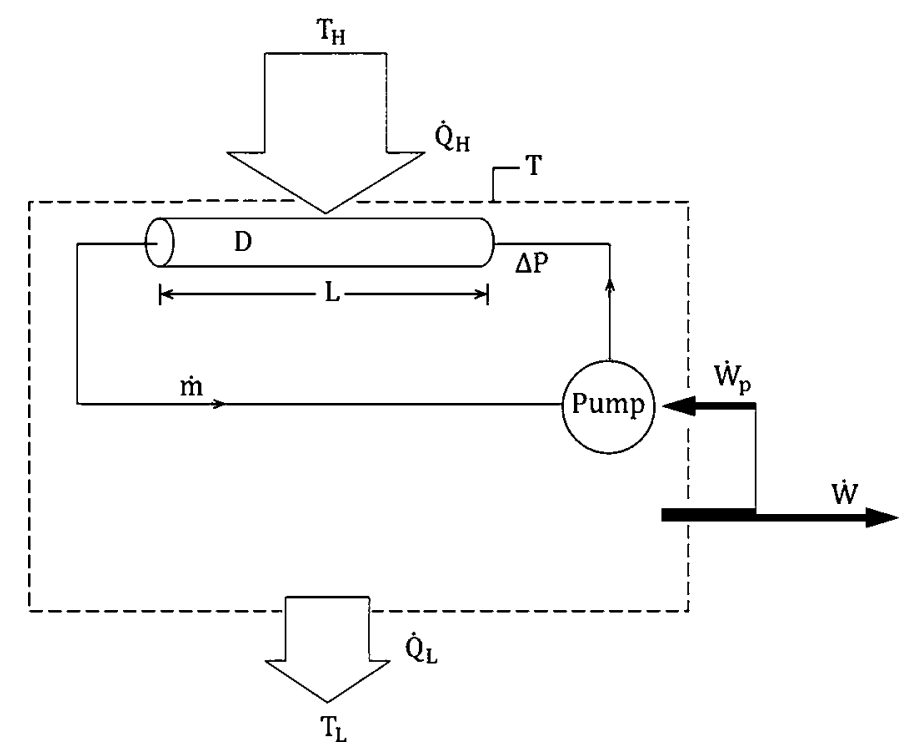

Figure 4: Model of steady-state engine with two irreversibilities due to 'finite size': heat transfer $\dot{\mathrm{Q}}_{\mathrm{H}}$ across a finite temperature difference $\left(\mathrm{T}_{\mathrm{H}}-\mathrm{T}\right)$, and fluid flow ( $\left.\dot{\mathrm{m}}\right)$ with pressure drop $(\Delta \mathrm{P})$ against a flow resistance. The finite size is associated with the duct with fluid flow and heat transfer: diameter $\mathrm{D}$, and length $\mathrm{L}$. The rest of the system defined with dashed line is free of irreversibilities. 
state. We identify two currents that are necessary, and which must overcome two resistances, one for heat transfer (HT) and the other for fluid flow (FF):

(HT) The heat input $\mathrm{Q}_{\mathrm{H}}$ is provided by the heat source of temperature $T_{H}$. The temperature difference $\left(T_{H}-T\right)$ is necessary because the area of thermal contact between the heat source $\left(T_{H}\right)$ and the hot side of the engine $(\mathrm{T})$ is finite and of order DL,

$$
\dot{\mathrm{Q}}_{\mathrm{H}} \sim \mathrm{hDL}\left(\mathrm{T}_{\mathrm{H}}-\mathrm{T}\right)
$$

The heat transfer coefficient (h) between the heat source and the duct surface is assumed constant.

(FF) The stream of working fluid that circulates through the engine (m) must overcome the resistance posed by the duct of length $\mathrm{L}$ and diameter $\mathrm{D}$. If the flow is single phase, turbulent and fully developed, the pressure drop along the duct scales as $\Delta \mathrm{P} \sim \dot{\mathrm{m}}^{2} \mathrm{~L} / \mathrm{D}^{5}$, and the required pumping power scales as $\dot{\mathrm{W}}_{\mathrm{p}} \sim \dot{\mathrm{m}} \Delta \mathrm{P} / \rho$, therefore

$$
\dot{\mathrm{W}}_{\mathrm{p}} \sim \frac{\dot{\mathrm{m}}^{3} \mathrm{~L}}{\rho \mathrm{D}^{5}}
$$

The rest of the engine model is free of thermodynamic irreversibilities. This means that the net power output is equal to the Carnot power associated with $\mathrm{T}$ and $\mathrm{T}_{\mathrm{L}}$, namely $\dot{\mathrm{Q}}_{\mathrm{H}}\left(1-\mathrm{T}_{\mathrm{L}} / \mathrm{T}\right)$, minus the pumping power requirement estimated in eqn (11),

$$
\dot{\mathrm{W}}=\dot{\mathrm{Q}}_{\mathrm{H}}\left(1-\frac{\mathrm{T}_{\mathrm{L}}}{\mathrm{T}}\right)-\dot{\mathrm{W}}_{\mathrm{p}}
$$

If the resistances HT and FF did not exist, the power output would be the Carnot power associated with $\mathrm{T}_{\mathrm{H}}$ and $\mathrm{T}_{\mathrm{L}}$,

$$
\dot{\mathrm{W}}_{\mathrm{rev}}=\dot{\mathrm{Q}}_{\mathrm{H}}\left(1-\frac{\mathrm{T}_{\mathrm{L}}}{\mathrm{T}_{\mathrm{H}}}\right)
$$

The efficiency of the nonideal model (Fig. 4) can be evaluated either as in the lower part of Fig. 3 (using the first law efficiency $\eta=\dot{W} / \dot{Q}_{H}$ ), or by using the second-law efficiency defined as

$$
\eta_{\mathrm{II}}=\frac{\dot{\mathrm{W}}}{\dot{\mathrm{W}}_{\mathrm{rev}}}
$$

The two efficiencies are proportional, $\eta / \eta_{I I}=1-T_{L} / T_{H}$, constant.

The physical dimensions $\mathrm{D}$ and $\mathrm{L}$ are proportional to the length scale of the engine, which in Fig. 4 is represented by the tube of mass $\mathrm{M} \sim \rho \mathrm{L}_{\text {scale }}^{3}$, where $\rho$ is the average density of the tube filled with working fluid. Writing

$$
(\mathrm{D}, \mathrm{L}) \sim \mathrm{L}_{\text {scale }} \sim\left(\frac{\mathrm{M}}{\rho}\right)^{1 / 3}
$$

and combining eqns (9)-(14), in the limit $\eta_{\text {II }} \rightarrow 1$ we obtain

$$
\eta_{\mathrm{II}}=1-\mathrm{C}_{\mathrm{HT}} \mathrm{M}^{-2 / 3}-\mathrm{C}_{\mathrm{FF}} \mathrm{M}^{-4 / 3}
$$


where the constant factors $\mathrm{C}_{\mathrm{HT}}$ and $\mathrm{C}_{\mathrm{FF}}$ account for the specified characteristics of the two flow resistances,

$$
\mathrm{C}_{\mathrm{HT}} \sim \frac{\mathrm{T}_{\mathrm{L}} \rho^{2 / 3} \dot{\mathrm{Q}}_{\mathrm{H}}}{\mathrm{hT}_{\mathrm{H}}\left(\mathrm{T}_{\mathrm{H}}-\mathrm{T}_{\mathrm{L}}\right)} \quad \mathrm{C}_{\mathrm{FF}} \sim \frac{\rho^{1 / 3} \dot{\mathrm{m}}^{3}}{\dot{\mathrm{W}}_{\mathrm{rev}}}
$$

The efficiency formula (15) explains why the size (M) matters to the efficiency of any engine. As the size increases, both flow resistances decrease in importance, and $\eta_{\text {II }}$ approaches the Carnot limit, $\eta_{\mathrm{II}}=1$. Noteworthy is the concavity of the $\eta_{\mathrm{II}}(\mathrm{M})$ relation, which is in accord with eqn (4). Assume that eqn (15) is represented by the simpler form

$$
\eta_{\text {II }}=1-\mathrm{C}_{2} \mathrm{M}^{-\mathrm{k}}
$$

where $k$ is a constant comparable with $2 / 3$ and $3 / 4$. Next, in eqn (5) replace $\eta$ with $\eta_{\text {II }}\left(1-T_{L} / T_{H}\right)$, and $\mathrm{M}_{\mathrm{m}}$ with $\mathrm{M}$. If we force eqn (17) and the modified eqn (5) to agree in value $\left(\eta_{\mathrm{II}}\right)$ and slope $\left(\mathrm{d} \eta_{\mathrm{II}} / \mathrm{dM}\right)$, then in the limit $\eta_{\mathrm{II}} \rightarrow 1$ the match is assured if

$$
\mathrm{a}=\frac{1-\eta_{\mathrm{II}}}{1-\mathrm{T}_{\mathrm{L}} / \mathrm{T}_{\mathrm{H}}} \mathrm{k}
$$

Note the absence of the factors $C_{1}$ and $C_{2}$. Although both $\left(1-\eta_{I I}\right)$ and $\left(1-T_{L} / T_{H}\right)$ are smaller than 1 , in the limit $\eta_{\text {II }} \rightarrow 1$ their ratio is smaller than 1 . In conclusion, $\alpha$ is comparable with $\mathrm{k}$, but on the low side of $\mathrm{k}$.

\section{RIVERS AS WATER MASS VEHICLES}

Larger rivers are more efficient as vehicles of water mass. This is not the usual view of what rivers accomplish, but it is easy to recognize by re-examining the traditional description of a river flowing in a channel in steady state. Assume that the channel is inclined at the small angle $\beta$. Its length is $\mathrm{L}$, and the relative height of its high end is $\mathrm{H} \sim \beta \mathrm{L}$. The channel depth and width are proportional to each other (this, to facilitate flow access [2]), and are represented by the transversal length scale D.

The water mass residing in the channel is $\mathrm{M} \sim \rho \mathrm{D}^{2} \mathrm{~L}$. This mass is pulled downstream by the longitudinal component of its weight $\mathrm{Mg}$, which is $\mathrm{Mg} \beta$. The downstream force is balanced by the upstream friction force posed by the river bed, $\tau \mathrm{DL}$, where $\tau$ is shear stress, $\tau \sim \mathrm{C}_{\mathrm{f}} \rho \mathrm{U}^{2}$, and $\mathrm{C}_{\mathrm{f}}$ and $\mathrm{U}$ are the skin friction coefficient (a constant of order 0.01 ) and $\mathrm{U}$ is the mean water speed. From this force balance results the water speed,

$$
\mathrm{U} \sim\left(\frac{\mathrm{g} \beta \mathrm{D}}{\mathrm{C}_{\mathrm{f}}}\right)^{1 / 2}
$$

With reference to eqn (3) then, the role of fuel in the river-mass vehicle is played by the gravitational potential energy, which is of order $\mathrm{MgH}$. The role of work of locomotion [namely, $\mu \mathrm{MgL}$ in eqn (3)] is played by the kinetic energy imparted to the body of water, which is of order $\mathrm{MU}^{2}$. Therefore the efficiency $\eta$ of eqn (3) becomes

$$
\eta \sim \frac{\mathrm{D} / \mathrm{L}}{\mathrm{C}_{\mathrm{f}}}
$$

and it shows that wider channels (larger D) are more efficient vehicles for moving water mass. 
Another way to see the physics meaning of eqn (20) is by asking how the work of locomotion $\mathrm{MU}^{2}$ is subsequently converted on a horizontal plain into moving the mass $\mathrm{M}$ to the new (longer) distance $\mathrm{L}_{\text {plain }}$, against the friction force $(\tau \mathrm{DL}) \mathrm{L}_{\text {plain }}$. From this follows $\mathrm{L}_{\text {plain }} \sim \mathrm{D} / \mathrm{C}_{\mathrm{f}}$ and the conclusion that larger rivers (larger $\mathrm{D}$ ) spread farther (to a larger $\mathrm{L}$ ) before they come to rest. Again, a larger size means a more efficient vehicle for moving mass horizontally.

\section{HIERARCHY OF MASS MOVERS}

Now think of a vehicle of mass $M_{1}=M_{s 1}+M_{m 1}$. Because of mass scaling for minimal fuel or food consumption, eqn (9), the mass of the vehicle is represented by a single mass scale, $M_{1}$. The mass scale of a vehicle of a different size is $M_{2}$. If there is one $M_{1}$ vehicle and $n$ vehicles of size $M_{2}$, then the total mass that moves on an area is

$$
\mathrm{M}=\mathrm{M}_{1}+\mathrm{nM}_{2}
$$

According to eqns (3) and (5), the amount of fuel required to transport a mass $\left(\mathrm{M}_{1}\right.$ or $\left.\mathrm{M}_{2}\right)$ to the distance $\mathrm{L}$ is proportional to $\left(\mathrm{M}_{1,2} / \mathrm{M}_{1,2}^{\mathrm{a}}\right) \mathrm{L}=\mathrm{M}_{1,2}^{1-\mathrm{a}} \mathrm{L}$, where $(1-\alpha)<1$ because $\alpha<1$. This means that the total fuel required to transport the total mass shown in eqn (21) is proportional to the sum

$$
\mathrm{m}_{\mathrm{f}}=\mathrm{m}_{\mathrm{f} 1}+\mathrm{nm}_{\mathrm{f} 2} \sim \mathrm{M}_{1}^{1-\mathrm{a}} \mathrm{L}_{1}+\mathrm{nM}_{2}^{1-\mathrm{a}} \mathrm{L}_{2}
$$

where $L_{1}$ is the distance traveled by $M_{1}$, and $L_{2}$ is the distance traveled by each of the masses $M_{2}$.

If the total mass (M) is fixed, then according to eqn (21) we have the freedom to select two variables, e.g. $M_{1}$ and $M_{2}$ (or $n$ ). The result of minimizing the $m_{f}$ expression (30) with respect to $M_{1}$ and $\mathrm{M}_{2}$ subject to the constraint (21) is

$$
\left(\frac{\mathrm{M}_{2}}{\mathrm{M}_{1}}\right)_{\mathrm{opt}}=\left(\frac{\mathrm{L}_{2}}{\mathrm{~L}_{1}}\right)^{1 / \mathrm{a}}
$$

This result is remarkable because it is n-independent, and it recommends the use of the smaller vehicles $\left(M_{2}\right)$ on the shorter route $\left(L_{2}\right)$. When eqn (23) holds, the total vehicle mass (29) becomes

$$
M=M_{1}\left[1+n\left(\frac{L_{2}}{L_{1}}\right)^{1 / a}\right]
$$

The minimal fuel requirement that corresponds to eqns (23) and (24) is

$$
\mathrm{m}_{\mathrm{f}, \min }=\mathrm{M}^{1-\mathrm{a}}\left(\mathrm{L}_{1}^{1 / \mathrm{a}}+\mathrm{nL}_{2}^{1 / \mathrm{a}}\right)
$$

Next, consider the rectangular area $\left(A=L_{1} L_{2}\right)$ that is swept by $M_{1}$ along $L_{1}$, and by the $n$ masses $M_{2}$ along $L_{2}$. The further minimization of $m_{f, \text { min }}$ with respect to $L_{1}$ and $L_{2}$ subject to $A=$ constant yields the optimal shape of the swept area

$$
\left(\frac{\mathrm{L}_{1}}{\mathrm{~L}_{2}}\right)_{\mathrm{opt}}=\mathrm{n}^{\mathrm{a}}
$$

and the minimum fuel requirement on $\mathrm{A}$, 


$$
\mathrm{m}_{\mathrm{f}, \text { min,min }}=2 \mathrm{M}^{1-\mathrm{a}} \mathrm{n}^{1 / 2} \mathrm{~A}^{1 / 2 \mathrm{a}}
$$

In the preceding analysis we viewed the moving masses as vehicles, and because vehicles result from complex processes of economics and manufacturing, the total vehicle mass (M) was used as reference. The analysis that followed was the search for the best way to distribute $\mathrm{M}$ among the large and small vehicles. The result of the double minimization of $\mathrm{m}_{\mathrm{f}}$, eqn (26), can be combined with eqn (23) to discover that the best way to allocate the vehicle mass is by partitioning it equally, one mass for one large vehicle, and an equal mass for all the vehicles of smaller size,

$$
\mathrm{M}_{1}=\mathrm{nM}_{2}
$$

An alternative way to allocate mass movement on $\mathrm{A}$ is to view the moving masses as the material (the load, the charge) that the vehicles are carrying. In other words, the loads are larger than the bodies of the vehicles themselves. The flow of load material is conserved, and this means that the load carried by the small vehicles (total mass $\mathrm{nM}_{2}$ ) is the same as the load carried by the large vehicle (mass $M_{1}$ ). This alternative view is represented, coincidentally, by eqn (28), in which $M_{1}\left(\right.$ or $\left.n M_{2}\right)$ is the specified mass that sweeps A.

The question is what varies, and how the configuration morphs such that the total fuel required for moving $\mathrm{M}_{1}$ on $\mathrm{A}$ is minimal. We answer this by minimizing the $\mathrm{m}_{\mathrm{f}}$ expression (22) subject to eqn (28) and $A=L_{1} L_{2}$. There are only two degrees of freedom, $n\left(\right.$ or $\left.M_{2}\right)$ and $L_{1} / L_{2}$. The result of the minimization with respect to $\mathrm{L}_{1} / \mathrm{L}_{2}$ is

$$
\begin{gathered}
\left(\frac{\mathrm{L}_{1}}{\mathrm{~L}_{2}}\right)_{\mathrm{opt}}=\mathrm{n}^{\mathrm{a}} \\
\mathrm{m}_{\mathrm{f}, \min }=2 \mathrm{M}_{1}^{1-\alpha} \mathrm{n}^{\alpha / 2} \mathrm{~A}^{1 / 2}
\end{gathered}
$$

These results are similar to eqns (26) and (27).

\section{NUMBER OF SMALL MASSES ALLOCATED TO ONE LARGE MASS}

Not determined at this point is the number $\mathrm{n}$, which accounts for how the total mass is allocated to the small $\left(\mathrm{M}_{2}\right)$ and the large $\left(\mathrm{M}_{1}\right)$. We show here that $\mathrm{n}$ depends on the pattern displayed by the masses as they sweep the area together, and that $\mathrm{n}$ can be selected such that the total fuel used on the entire area is minimal.

For illustration, start with the square area shown in Fig. 5, which has four area elements of size $\mathrm{L}_{0}^{2}$. Each elemental area is traveled by a small (elemental) mass $\mathrm{M}_{0}$ along a path of length $\mathrm{L}_{0} / 2$. The large mass that travels the area (in or out) is $4 \mathrm{M}_{0}$.

The path followed by the mass of size $4 \mathrm{M}_{0}$ is not unique. In Fig. $5 \mathrm{a}$, the mass $4 \mathrm{M}_{0}$ is constituted after two consecutive pairings of the small mass. After the first pairing, each mass of size $2 \mathrm{M}_{0}$ travels the distance $\mathrm{L}_{0} / 2$. After the second pairing the mass $4 \mathrm{M}_{0}$ travels the distance $\mathrm{L}_{0}$. The fuel required by this entire mass movement is calculated (one mass at a time) by using eqn (22) and accounting for every mass,

$$
\mathrm{m}_{\mathrm{f}, 5 \mathrm{a}}=\mathrm{M}_{0}^{1-\mathrm{a}} \mathrm{L}_{0} 2^{2}\left(\frac{1}{2}+2^{-(1+\mathrm{a})}+2^{-2 \mathrm{a}}\right)
$$

An alternative flow pattern is used in Fig. $5 \mathrm{~b}$, where the four $\mathrm{M}_{0}$ movements are attached to a stem of length $3 \mathrm{~L}_{0} / 2$. The mass that moves along the stem is $2 \mathrm{M}_{0}$ along $\mathrm{L}_{0}$, followed by $4 \mathrm{M}_{0}$ along $\mathrm{L}_{0} / 2$. The total fuel is calculated (mass by mass) using eqn (22), 


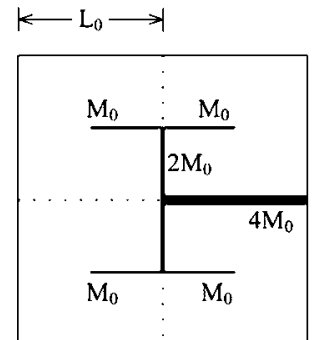

(a)

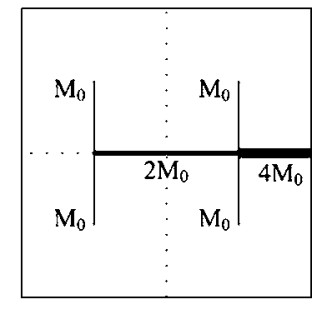

(b)

Figure 5: Two ways in which four small masses $\left(\mathrm{M}_{0}\right)$ coexist with one large mass $\left(4 \mathrm{M}_{0}\right)$ as they sweep the same area. Design (a) is based on two successive pairings of small masses into larger masses. Design (b) has a stem: the four masses are moving to (or from) a central stem traveled by the large mass.

$$
\mathrm{m}_{\mathrm{f}, 5 \mathrm{~b}}=\mathrm{M}_{0}^{1-\mathrm{a}} \mathrm{L}_{0} 2^{2}\left[\frac{1}{2}+2^{-(1+\mathrm{a})}+2^{-(1+2 \mathrm{a})}\right]
$$

The first conclusion is that the design with stem (Fig. 5b) is better, because $m_{f, 5 b}<m_{f, 5 a}$. But, is the $n=4$ pattern with stem the best? In other words, should four small masses always be allocated to one large mass? To answer this question we turn to Fig. 6, which shows the general case of a square area with $n$ masses. Start with the movement of mass on the very slender area $(\mathrm{N} / 2) \mathrm{L}_{0} \times 2 \mathrm{~L}_{0}$ shown in Fig. 6a. There are N/2 elemental areas and masses on each side of the stem. Next, assume that $\mathrm{N} \gg>1$, therefore the length of the stem approaches $(\mathrm{N} / 2) \mathrm{L}$, and the mass that moves along the stem is distributed almost linearly, from zero at the left end to $\mathrm{NM}_{0}$ at the right end. The total fuel required to move all the masses on Fig. 6a is calculated with an equation such as eqn (22).

Finally, we use $\mathrm{N}$ of the slender designs of Fig. $6 \mathrm{a}$ in order to make the square-area design shown in Fig. 6b. Now there are N/2 slender designs on each side of a stem of length that approaches (N/2) $\left(2 \mathrm{~L}_{0}\right)$. The mass varies almost linearly along this new stem, and reaches $\mathrm{N}^{2} \mathrm{M}_{0}$ at the right end. The total fuel requirement is $\mathrm{N}$ times the fuel calculated in the preceding paragraph plus the fuel for moving the mass along the stem of Fig. $6 \mathrm{~b}$. The result is

$$
\mathrm{m}_{\mathrm{f}, 6 \mathrm{~b}}=\mathrm{M}_{0}^{1-\mathrm{a}} \mathrm{L}_{0} \mathrm{~N}^{2}\left[1+\frac{\mathrm{N}^{1-\mathrm{a}}}{2-\mathrm{a}}\left(1+\mathrm{N}^{-\mathrm{a}}\right)\right]
$$

Equations (33) and (32) have the same form. The size of the square domain is $\left(\mathrm{NL}_{0}\right)^{2}$, or $\mathrm{nL}_{0}^{2}$, and the number of elemental masses that reach the main stem is $\mathrm{n}=\mathrm{N}^{2}$. Furthermore, eqn (32) represents the special case $\mathrm{N}=2$ (or $n=4$ ) of eqn (33). The total fuel requirement increases with the size of the territory $\left(\mathrm{NL}_{0}\right)^{2}$, and with the factor shown in the square brackets. That factor represents the fuel spent per unit area, and it is minimum when

$$
\mathrm{N}_{\mathrm{opt}}^{\mathrm{a}}=\frac{2 \mathrm{a}-1}{1-\mathrm{a}}
$$

We just discovered that $\mathrm{N}$ ( or $\mathrm{n}$ ) should have a particular value, which is dictated by the 'economies of scale' exponent $\alpha$. Special is the case $\alpha=2 / 3$ when $\mathrm{N}_{\text {opt }}=1$. The number $\mathrm{N}_{\text {opt }}\left(\right.$ or $\left.\mathrm{n}_{\text {opt }}\right)$ increases as 


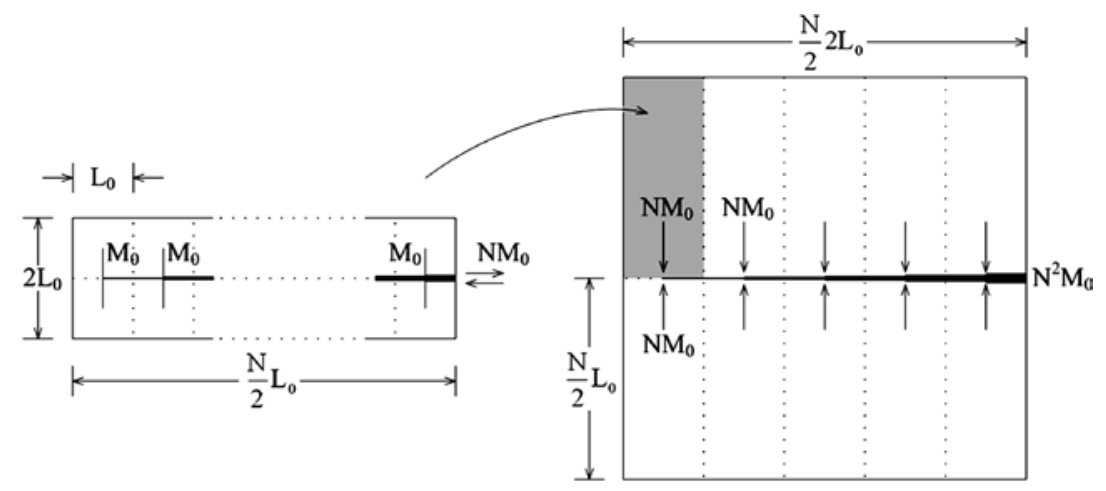

(a)

(b)

Figure 6: The construction of mass movement of a large square area traveled by $\mathrm{N}^{2}$ small masses $\mathrm{M}_{0}$, which feed (or are fed by) a large mass that moves along a central stem. Design (a) shows how to distribute $\mathrm{N}$ masses to an intermediate stem of length $(\mathrm{N} / 2) \mathrm{L}_{0}$. Design (b) is the square construction in which $\mathrm{N}$ designs of type (a) are connected like leaves on a main stem. Note that design (b) is the general version of the design of Fig. $5 b$ (which is the special case $N=2$ ).

$\alpha$ increases from $2 / 3$ to 1 . If $\alpha=3 / 4$, then $\mathrm{N}_{\text {opt }}=2^{4 / 3}$ and $\mathrm{n}_{\mathrm{opt}}=4^{4 / 3}$, which is approximately the same design as the $n=4$ design used in Fig. 5b. In conclusion, the construction rule of allocating four small masses to one large mass (Fig. 5b) is recommended when $\alpha$ is comparable with $3 / 4$. This construction is consistent with eqn (29), where if we substitute $\mathrm{L}_{1}=(3 / 2) \mathrm{L}_{0}$ and $\mathrm{L}_{2}=(1 / 2) \mathrm{L}_{0}$ (cf. Fig. 5b), we obtain $\mathrm{L}_{1} / \mathrm{L}_{2}=3$, which is comparable with $\mathrm{n}^{\mathrm{a}}=4^{3 / 4}=2.83$.

\section{CONCLUSIONS}

In this paper we showed that the constructal law commands the emergence of hierarchy in the movement of mass on earth. The movement on an area is accomplished with greater ease when the mass travels in bodies of multiple scales. The large must be few, and the small must be many. There must be a certain number of small bodies that are 'allocated' to a larger body, as they all move on the area.

The movement of mass as vehicles and animals is ruled by the same constructal law that accounts for the emergence of hierarchy in river basins. The moving bodies analyzed in this paper are analogous to and more general than the parcels of water in the river basin, and eddies in a turbulent flow. The vehicles and animals are self-driven - they transform fuel and food on board - whereas the water parcels are driven by gravitational potential energy, and the eddies are driven by their kinetic energy.

Here is an even simpler way to see why 'few large and many small' should be the design that emerges naturally, according to the constructal law. Analytically, the description of the flow of mass is analogous to the description of the flow of water in river channels:

$\begin{array}{lcc} & \text { Vehicles } & \text { Rivers } \\ \text { Dissipation (fuel, power) } & \mathrm{m}_{\mathrm{f}} \sim \frac{\mathrm{ML}}{\mathrm{M}^{\mathrm{a}}} & \dot{\mathrm{W}} \sim \frac{\dot{\mathrm{m}}^{3} \mathrm{~L}}{\mathrm{D}^{5}} \\ \text { Mass conservation } & \mathrm{M}_{1}=\mathrm{nM}_{2} & \dot{\mathrm{m}}_{1}=\mathrm{nm}_{2}, \quad(\mathrm{n}=4, \text { Horton's rule }[6,16])\end{array}$


The difference between the two classes of flow systems is that in river channels the thickness of the channel is represented by $\mathrm{D}^{5}$, while in vehicles is $\mathrm{M}^{\mathrm{a}}$.

Several other features of the mass movement design follow from the same law. The larger bodies must travel the longer distance on the fixed area. If the moving mass is a vehicle (or animal), the motor (muscle) mass must scale with the structural (skeleton) mass, and with total mass. The larger vehicles and animals are more efficient than the smaller. The 'few large and many small' pattern is an integral part of the global design.

\section{ACKNOWLEDGEMENT}

This research was supported by the National Science Foundation.

\section{REFERENCES}

[1] Bejan, A. \& Lorente, S., Design with Constructal Theory, Wiley: Hoboken, 2008. doi:10.1002/9780470432709

[2] Bejan, A., Advanced Engineering Thermodynamics, 2nd edn, Wiley: New York, 1997.

[3] Bejan, A. \& Lorente, S., Constructal theory of configuration generation in nature and engineering. J. Appl. Phys., 100, pp. 041301, 2006. doi:10.1063/1.2221896

[4] Reis, A.H., Constructal theory: from engineering to physics, and how flow systems develop shape and structure. Appl. Mech. Rev., 59, pp. 269-282, 2006. doi:10.1115/1.2204075

[5] Poirier, H., A theory explains the intelligence of nature. Science \& Vie, 1034, pp. 44-63, 2003.

[6] Reis, A.H., Constructal view of scaling laws of river basins. Geomorphology, 78, pp. 201-206, 2006. doi:10.1016/j.geomorph.2006.01.015

[7] Constructal Theory Web Portal, www.constructal.org.

[8] Bejan, A. \& Marden, J.H., Constructal unification of biological and geophysical design, Physics of Life Reviews, 6, pp. 85-102, 2009. doi:10.1016/j.plrev.2008.12.002

[9] Reis, A.H., Miguel, A.F. \& Aydin, M., Constructal theory of flow architecture o the lungs. Medical Physics, 31, pp. 1135-1140, 2004. doi:10.1118/1.1705443

[10] Miguel, A.F., Constructal pattern formation in stony corals, bacterial colonies and plant roots under different hydrodynamics conditions. J. Theor. Biol., 242, pp. 954-961, 2006. doi:10.1016/j.jtbi.2006.05.010

[11] Reis, A.H. \& Gama, C., Sand size versus beachface slope - an explanation based on the Constructal Law. Geomorphology, 114, pp. 276-283, 2010. doi:10.1016/j.geomorph.2009.07.008

[12] Bejan, A. \& Marden, J.H., Unifying constructal theory for scale effects in running, swimming and flying. J. Exp. Biol., 209, pp. 238-248, 2006. doi:10.1242/jeb.01974

[13] Bejan, A., Lorente, S., Miguel, A.F. \& Reis, A.H., Constructal theory of distribution of city sizes. Advanced Engineering Thermodynamics, 3rd edn, A. Bejan, Wiley: Hoboken, 2006.

[14] Bejan, A., Lorente, S. \& Lee, J., Unifying constructal theory of tree roots, canopies and forests. J. Theor. Biol., 254(3), pp. 529-540, 2008. doi:10.1016/j.jtbi.2008.06.026

[15] Kim, Y.S., Lorente, S. \& Bejan, A., Distribution of size in steam turbine power plants. Int. J. Energy Research, 33, pp. 989-998, 2009. doi:10.1002/er.1528

[16] Bejan, A., Lorente, S., Miguel, A.F. \& Reis, A.H., Constructal theory of distribution of river sizes. Advanced Engineering Thermodynamics, 3rd edn, A. Bejan, Wiley: Hoboken, 2006. 